Kohl: a Journal for Body and Gender Research

Vol. 4, No. 1 (Summer 2018)

\title{
ICTs as the Bullring: A Case Study of the Rainbow Flag Incident in Cairo
}

Lara Mansour

\begin{abstract}
:
In this paper I am studying an incident that started with a concert in one of Cairo's upper middle class districts, and ended up with a crackdown on the LGBTIQA++ Community in Egypt. In that incident Information Communication Technologies (ICTs) played a main role of contesting positions and representations of state and LGBTIQA++ persons in Egypt. Through the following lines, I am trying to unfold the intricacies of ICTs usage among both the state apparatuses and representatives of their discourse online on the one hand, and the LGBTIQA++ people and allies narratives. And how is it that this very same space acted as a presenceand forced absence- for both. My study is based on personal interviews with members who were directly involved in these events.
\end{abstract}




\section{Introduction}

Friday, September 22, 2017 started as an exciting week-end for those who were planning to attend the concert of the Lebanese band Mashrou' Leila in Cairo. The concert took place in the middle-upper class commercial space "Cairo Festival City," which also featured other contemporary bands. The earlier excitement dwindled as the night progressed, starting with the testimonies of harassment at the gates, all the way to the retaliations for raising the Sexual Diversity Pride flag (also called Rainbow Flag). Some of members affiliated ${ }^{1}$ with the LGBTIQA $++^{2}$ community saw the raising of the rainbow flag as fitting to the event, since Mashrou' Leila's lead singer, Hamed Sinno, is openly gay.

Following the concert, the Egyptian police orchestrated a massive crackdown on homosexual, queer, and trans* people. The crackdown was coupled with an artillery media propaganda and a social media flare in what came to be known as "the Rainbow Flag incident." The state discourses justified the mass arrest and the propaganda under the guise of national protection against "vice," but these justifications are far from being novel - they have been occurring since 2013 according to Dalia Abdel-Hamid (Mada Masr, 2017b), the head of the Gender and Sexuality program at the Egyptian Initiative for Personal Rights (EIPR). According to the legal support team of an Egyptian LGBTQIA++ organization (interview with Bedayaa LGBTQI in the Nile Valley, 2018), they knew of 77 cases of arrest; of these, only two to three had actually attended the Mashrou' Leila concert, and only one of them had raised the rainbow flag. As for the rest of the detainees, they were either electronically "trapped," a notion I go back to later, and subsequently arrested from their houses, or apprehended in pick-up places known to the middle and working class gay men in central Cairo and Giza.

In the following paper, I attempt to investigate the role of social media, particularly Facebook, as the bullring: a site of state discourse and national moral protection on the one hand, and a place for gathering, support, and contestation of identity and representation on the other. I intend to analyze this incident by providing a brief on the internet scene in Egypt and its role in political and social mobilization. Alluding to the history of the crackdowns on LGBTIQA++ identities, I then highlight the means of monitoring arrests and their legal gaps. I base this analysis on an EIPR report titled "The trap: Punishing Sexual Difference in Egypt" (AbdelHamid, 2017), which documents four years of hindering and cracking down on members of the LGBTIQA++ community in Egypt, but also on my own knowledge and experience of the past seven years in working at/with civil society organizations, and participating in debates on the laws corresponding to gender, sexuality, and cyber-security in Egypt. Afterwards, I look at the Mashrou' Leila concert as an "event," or a rupture that disrupts the order of things, to heed Badiou (2005, p. xxvi; Norris, 2009, p. 9). In that sense, a rupture would

1 By "affiliation" and "membership," I designate people who use one - or more - of the acronym LGBTIQ++ to define their gender and/or sexual orientation. Some of those are the people I have interviewed for this paper, and others are people of knowledge who have attended the concert.

2 The acronym for Lesbian, Gay, Bisexual, Transexual/Transgender, Queer, Intersex, Asexual, and More (LGBTIQA++) is used in this research to describe all people self-define using one or more of these terms. I have also chosen to use it as an umbrella term to refer to gender non-conforming individuals, whether or not they choose to engage in same sex behavior or cis-gendered performativity. 
redefine the meaning of a signified, leading to a transformation. In short, by analyzing ICTs, this paper looks at an event as a place of identitarian contestations, highlighting the notion of the personal as political and vice versa. It also aims to investigate the offline and online spectrum without capitalizing on the binary, since they are both part and parcel of contemporary existence.

\section{A Note on Methodology and Scope}

I am basing this study on participant observation and semi-structured interviews. I was privy to the debates on secret Facebook groups for LGBTIQA++ members before, during, and after the concert. I also witnessed the online crack-downs on social media through the official Facebook pages, posts of the Egyptian police, and media platforms that adopted the state discourse, and followed the online and offline actions of human rights defenders and organizations. I conducted simple and basic interviews with LGBTIQA++ community members, from the concert attendees to the administrators of the secret Facebook pages, who found themselves directly affected by the retaliations. I also talked to members in organizations that helped in providing legal and non-legal support, and ensured that the online information on the arrests, propagated among the community, was authenticated. My notes therefore consist of blackened screenshots, field notes from direct interviews, encrypted recordings, or conversations among activists and/or researchers, myself included. I obtained consent from all parties involved to use these notes.

In regards to the geography of my field of study, I base the contours of what Egypt means on what a geography is in terms of cyber-ethnographies, according to the studies of digital ethnography scholars. ${ }^{3}$ In that sense, one can assert that the enmeshment of our online and offline existences can be mapped. These embodiments are not two faces of the same coin, in that it is "us" as an individual, but more of a matrix of complex actions and reactions between "us," the unit, on the one hand, and "us," the social, on the other. Geography, then, is not only the simplistic notion of Internet Protocol addresses (IP) that tickets us into the heterotopia of the internet, or official documents that slots us whenever and wherever its issuers desire. Geography - or Egypt in this context - is those who lived/ live in Egypt, and consequently live Egypt, whether they hold an Egyptian nationality on papers, or are refugees and foreigners, or even live abroad but still affiliate in one way or another to that (moral, social, political, cultural) geography. It is the political space in the personal space, and vice versa, the here and there, and the political and personal enmeshed.

\footnotetext{
3 See: Hine, C. (2015). Ethnography for the Internet: Embedded, Embodied and Everyday. Huntingdon: Bloomsbury; Bell, D. (2001). An Introduction to Cybercultures. London: Routledge; Gehl, R.W. (2014). "Power/freedom on the dark web: A digital ethnography of the Dark Web Social Network." New Media \& Society, vol. 18, no. 7, 2016, pp. 12191235; Green, E. (2013). "Mapping the 'Geography' of the Internet." The Atlantic, September 9, 2013. Available at: https://www.theatlantic.com/technology/archive/2013/09/mapping-the-geography-of-the-internet/279434/
} 
Free DSL Internet was introduced to Egypt in 1992, starting with a dial-up service brought by the main telecom company, Orascom. Then, the head telecom company installed free DSL service in the late 90 's and the turn of the millennium. Back then, chatting platforms like ICQ, Yahoo Messenger MSN Messenger, and other online platforms with variable virtual reality environment integrations, such as IMVU and Second Life, were used for socializing.

Currently, Egypt has 5 Internet Service Providers (ISP), and the Internet's development plans are mainly institutional and institutionalized for the time being (Ministry of Communication and Information Technology, 2017). Meanwhile, in terms of population and age groups, a report (2017) by the International Telecommunication Union (ITU) found that $60-80 \%$ of Egyptians between the ages of 15-24 are active users of the Internet. Consequently, these users shape the content that is shared online and the language in use, and redefine the spaces of debate and contestation. The 2010 uprisings in Tunisia and their echoing in the January 25, 2011 Egyptian revolution are an indicator of this shifting online cartography.

Two days after the break-out of the January 25 revolution, people within the IP region of Egypt tried to go online, to no avail. As Lori Andrews puts it, "the Mubarak regime has pulled the plug off internet in Egypt" (2012, p. 61). However, an investigation conducted by Renesys ${ }^{4}$ suggested that the Egyptian Government had ordered the then four main telecom companies to withdraw their Border Gateway Protocol. In other words, Internet was working, but the entity that provided the service from the international cables to the local geography of Egypt was intentionally closed (Andrews, 2013). This incident sets a precedent in terms of the Egyptian state's realization of the power of internet services on political mobilization, leading to legislative procedures to place ICTs under control. Protesters, however, managed to find alternative ways to communicate to geographies outside of Egypt, making use of fax machines, dial-up modems, BlackBerry's network - BBM was the only Instant Messaging service that was not under the network authority of any state, and "piggie-backing" neighboring countries' connection near the borders. In a paper on virtual representation in Second Life's 3D MMORPG Environment, Fouda (2016) also found out that some people took a little virtual island called Egypt on Second Life to chat with each other, including with families and friends, in the guise of Avatars, and discuss the political situation freely.

Throughout the seven years I spent reading, attending, and giving workshops on cyber-security, internet governance, and cyber ethnographies, I have noticed that some cyber-activists, human rights activists, and advocates oscillate between technophilia and technophobia ${ }^{5}$ when it comes to the enmeshment of ICTs in our everyday. A realistic view of the cyberspace would reveal the following: firstly, social media is a mosaic

${ }^{4}$ Renesys, the Internet Intelligence Authority, is a private internet research company that conducts business-tobusiness real-time internet transparency researches for marketing and sales purposes. https://b2b.renesys.com/about/index.shtml

5 Technophilia is the extreme association to and enthusiasm for technology and its role in our everyday life. Technophobia, on the other hand, is the intense fear and hate of technology to the extent of attributing unrealistic capabilities to technology. 
of our declared and declared-by-the-fact-of-censorship ideas and representations. Therefore, by virtue of being away from state surveillance, it allows for the manifestation of the hegemonic and the counterhegemonic. Secondly, with a large percentage of youth involvement, mobile-cellular network penetration, and the presence of dark-web, document, and movie piracy, there is an increasing awareness of the doublebladed nature of social media usage on the one hand, and the potentialities of internet as technically limitless on the other. In other words, no policy would potentially be able to fully cut people off of communication or knowledge portals. Thirdly, cultural and moral policing is definitely one of the main signs of social media; while the Internet's technology facilitates the exchange of information and capital, and challenges the spatiotemporal dimensions, there is nothing in it that is absolute except for its possibilities of freedom. One just has to have the knowledge and access to get there.

Based on the aforementioned personal experience and research, I have also noticed a wider grasp and articulation of mass surveillance. With the increase of "margin," 6 if one did not hear about arrests because of cyber-activism, they could have heard about those who were tried for online satire before a court martial. If individual cases escaped one's attention, they might still know about the state representatives preaching about the "proper" use of social media, or the mistaken propaganda about hacking and hackers; one might even be part of that team, or have a friend who, wrongly accused of belonging to the Muslim Brotherhood, was arrested and had his phone confiscated. In other words, the past seven years witnessed waves of censorship and surveillance that were not limited to the LGBTIQA++ community (Hamama, 2017). Online censorship and surveillance led to a shift in the online consumption of personal lives. While more people switched from WhatsApp to Signal, others still choose to use unsecure applications; however, the change (or lack of) in the landscape is still sustained by a now-widespread epistemology of mass surveillance.

\section{The Intersections of State Legislations, Homosexuality, and Cyber-culture}

Since the turn of the 20th century, the Egyptian gay dating scene has been shaped by popular culture. Gay men, who had more access to public spaces than their women counterparts, had to generate a code language that acted as a signifier among their peers and in spaces such as pubs, bars, and local streets. This language - that is as discrete as the Fight Club rules - is still employed today, and includes verbal cues as well as physical gestures. Many oral resources assert that this language was inherited from the ancient belly dancers scene, dubbed el 'Awalem. Most ancient and modern Egyptian movies about the lives of belly dancers feature the figure of the feminine boy, or Sabi el 'Alma (the master dancer's boy), who follows the main dancer and tutor, el-M'allema, wherever she goes. A popular icon, Sabi el 'Alma became a stereotype that was made to represent almost all gay men, making it hardly possible for the social imaginary to make sense of a more contemporary depiction of homosexuality. For instance, the character of Hatim Rasheed in Alaa' El-Aswani's "The Yacoubian Building" is the editor-in-chief of a distinguished French-speaking newspaper; considered of a higher social class, he engages in a sexual relationship with the janitor. To the Egyptian public, the image

\footnotetext{
${ }^{6}$ By margin, I indicate those who are marginalized by the state apparatuses and labeled as a "threat" or an "anomaly" for social, economic, personal, or ideological reasons.
} 
of the "respectable" gay man strutting in the streets of downtown Cairo was still unpalatable and only gained visibility with the expansion of the electronic media and the creation of gay dating websites in the late 90s and early 2000s. Despite the precarity of unsafe online spaces as sites of cruising, it was a transgression. Gradually, social media then became the locality where this language is practiced, discussed, and contested, albeit within closed groups.

While the Egyptian state's treatment of gay men was heterogeneous across regimes in power and contexts, the modern Egyptian penal code does not criminalize homosexuality, as it is not recognized as a social act by the legal system in the first place. It is not the case with sex work: talking about negotiating or engaging in sexual services in exchange for money is still considered a criminal offense under article 10/1961 (AbdelHamid, 2017). It is this article of the penal code that is used to target gay men and trans* people, transwomen in particular. Despite the common societal rejection of homosexuality in the Egyptian geography, two longstanding ministers under the Mubarak regime were "known" to be gay, and so were a multitude of public figures, such as actors and newspapers editors.

Therefore, the Mubarak regime's crackdown on the Queen Boat in May 2001 came as a surprise to human rights researchers and lawyers alike, who had their values put to the test. As Gasser Abdel-Razeq, the head of EIPR, recalls, "the only incident of such a massive scale and wide media exposure prior to the Queen Boat case was that of the 'devil worshippers' [in the late 1990s]" (Mada Masr, 2017a). While Dalia Abdel-Hamid considered that all the Egyptian regimes used crackdowns to defer and distract from other issues, such as economic crises, with moral panic as their social fuel, Abdel-Razeq attributed the distraction strategy to the Mubarak era, distinguishing it from the current regime's crackdown on non-normativity as an instrument of nation-building (Mada Masr, 2017a). It is evident that the current Egyptian regime's moments of LGBT and NGOs censorship "fetish" increase at times of human rights violations in order to defer the public's attention. For instance, following the upload of a YouTube video of a gay wedding party on a felucca in 2013, the regime initiated a wave of LGBTIQA++ arrests. I was reminded of the correlation between the hype behind LGBTIQA++ arrests and those targeting several civilians protesting the anti-protest law in front of Al-lttihadiya presidential palace (Fouda, 2014). Yet, Abdel-Razeq was also right in that the persistence of the regime's persecution of gay men and transwomen is symptomatic of a profound misogynistic creed that legitimizes certain forms of manhood, attributing them to either "religion" or "traditions." This automated mechanism, geared by ideological apparatuses, serves to further enhance such a discourse.

Since the Queen Boat case, gay men have mainly been targeted on the World Wide Web (www): fake accounts would convince webpage administrators (admins) that the owners of the accounts are potential lovers or clients. After exchanging messages by Instant Messaging (IM), they would lure the men to a meeting spot, subsequently ambushing them. EIPR's report (Abdel-Hamid, 2017) observed that Cairo's geography is placed high on the arrest map. Those arrests are especially conducted in the spots known to be gay meeting and cruising areas, such as Dokki in Giza, and Ramsis street and Culott Bek streets, both in downtown Cairo. 
Mostafa ${ }^{7}$ is a young, gay, middle class college student. Originally from Upper Egypt, he is currently living in Cairo. His early encounters with the Internet shaped his knowledge of and the dimensions and questions around his sexual orientation, as is the case for many of us. Mostafa told me that, in addition to the good old cafes and the pubs scene, websites were the pick-up spot for gay men in Egypt. For those born in the late 80 s and forward, the WWW was a cultural turning point. Before then, the cultural categorization of identity under the LGBTIQA++ acronym was far from being widespread; instead, gay men communicated through gestures and coded language, which did not necessarily translate into the articulation of an identity. Labels, in that sense, became the new hype, and are still in the process of crafting their localization in accordance with the community-specific language. Additionally, the WWW played a great role in all sexualities' "comingof-age" period, whereby porn sites, health sites, and personal blogs constituted the subliminal foundation of gathering and information sharing, from HIVIAIDS, to gay-friendly spots in Egypt. In that sense, gay men who grew up before the advent of the free internet resorted to different routes to access knowledge. Since the landscape and archival work of contemporary, pre-internet LGBTIQA++ studies in Egypt are lacking, the available literature refers to a more "historical period," such as the Ottoman occupation. Therefore, our collective knowledge of non-normative lives in the Nasser, Sadat, and pre-Queen Boat, early Mubarak eras remains limited.

Meanwhile, for the children and teenagers of the 90s and 2000s, such as Mostafa and the majority of my interlocutors, the internet was, in and of itself, an event in the Badiouan sense, in that it affected sexualities and sexual knowledge and behavior. However, the "abrupt" and "sudden" rupture Badiou described still ripples today where the internet is concerned: when the Mubarak regime legislated the internet and its uses in homes and computers at relatively low prices, it could not have envisioned that it was democratizing a tool for young people to articulate dissent and oppose that very same regime, nor could it foresee the eventual organizing of LGBTIQA++ cyber-protests.

\section{Navigating the "Leila"}

Prior to the Mashrou' Leila concert, anticipation and excitement reigned among the virtually active LGBTIQA++ members of the "Banana Republic"9 secret Facebook group. The members of the group who were planning to be at the concert shared photos of rainbow flags being sewn, prompting the group to discuss the pros and cons of a collective raising of the flag. I had offline, informal discussions after the concert, while the crackdown was still ongoing; one such discussion was with Ghaly. ${ }^{10} \mathrm{~A}$ fellow researcher and activist on gender and sexuality, Ghaly asserted that "of course, the event was a matter of visibility not recognition that is what it was about in the first place." He was responding to my recalling of Audra Simpson's study on "Indian" indigeneity - a self-definition by Simpson herself - in the reservations, and her definition of visibility

\footnotetext{
${ }^{7}$ All names of individuals or social media groups have been modified for security reasons.

8 "Leila" in Arabic, also written "laila," translates to "evening" in English.

9 lbid.

10 lbid.
} 
and recognition. For Simpson (2014), visibility serves to be seen or rendered visible and legible, but the ways through which one is seen and acknowledged do not necessarily happen on the terms of those seeking that visibility. At the time of our argument, I contended that while raising the flag might have been a matter of visibility, it was not necessarily what LGBTIQA++ community members should have striven for. However, upon acknowledging the complexities, diversities, and stances of the struggles of LGBTIQA++ members, I came to realize that Ghaly's point of view was shared by some members who were present at the concert. To them, visibility was a significant political act.

The euphoric state carried on throughout the concert and the morning after. Some of the attendees posted their pictures on the Facebook group or shared that they were waving to the camera drones that floated among the crowd. "Banana Republic" members considered the "event" of raising the flag as an iconoclast to the previous era that rendered invisible and illegible. Groups of LGBTIQA++ organizations in Egypt celebrated the rupture instigated by arms waving the rainbow flag among the concert's massive crowd as a speech act: sexual diversities are here, and everywhere.

On the "Banana Republic" group, the collective community panic started to unfold on the 26th of September. With the news of the first arrest, the community's activists spread digital and personal safety awareness posts, and members of the group started fact-checking who had been definitely apprehended and who wasn't. They confirmed the arrests by sharing posts from lawyers and activist groups in order to quiet down the climate of panic and limit the spread of rumors as early as possible. They also kept checking on those who were present at the concert. With the admins fearing that the online groups might be uncovered or infiltrated, some LGBTIQA++ groups got deleted; while "Banana Republic" decided to stay, the admins changed the group's original name and URL. These measures, whether leading to groups disappearing or changing their name, were not taken without long and emotionally charged debates. Samira, ${ }^{11}$ a group admin/member, NGO worker, and activist, informally recounted to me the lengthy and exhausting exchanges that took place between members inside and outside of Egypt, allies, and cybersecurity specialists, on whether to close the groups or not. Most of the NGOs working on LGBTIQA++ issues in Egypt had to take the decision to put their online presence on hiatus, but they managed to archive their digital imprint and existence. As for community workers and admins, they had to stay off the radar; Samira restricted her mobility around the country after her name and that of the organization she worked for were leaked on national television broadcasts. On the other hand, groups like "Banana Republic" and "Apple Pies" chose to persevere with their online presence. Mostafa, who administrated a group himself, recalled that such a decision required caution at a time of socially charged moralities and targeting of the online LGBTIQA++ community. The decision not only entailed ensuring the safety of one individual, but that of the collective as well, and called for more active communication to avoid feelings of being left in the dark among members.

Mostafa and Nesma, ${ }^{12}$ another member of the "Banana Republic" group, both agreed that the persistence of the group after the Rainbow Flag incident was beneficial for them on the personal and affective levels. The

\footnotetext{
11 lbid.

12 lbid.
} 
group played a leading role in opening the space for people to post about their panics, accidents, and attacks after the concert, and to engage with each other in the comments. Admins, like Mostafa, provided safety numbers in case of emergency, such as connections to shelters, safe houses, and legal assistance, going as far as overseeing the total deactivation of any Facebook profile upon the report of their user's arrest. NGO members or admins' thorough knowledge of cybersecurity protection procedures and protocols was not the only way to ensure these cyber counteractions; a direct connection with the Facebook development and administration team proved to be most useful, as Mostafa revealed to me during our interview. In parallel, the members of the group, through their various connections, knowledge spheres, levels of involvement, and experience with previous crack-downs and supporting procedures, acted as support systems for each other, as was apparent in the group debates at the peak of the crackdown. Some members posted to vent about the domestic pressure or to divulge that their parents had found out about their sexual orientation. The exchange prompted other members to share their own memories of similar experiences, providing emotional support to the original posters, on the group or privately. Other members constantly sent messages with the contact of gay-friendly doctors of different specialties, especially psychotherapy, or followed up with active members' sudden silence, making sure they were simply taking time off of Facebook.

Nesma's reaction, however, presented another view of the group's activity and how it affected her pre and post-concert. Not only does it open a portal of debate, but it also makes some cracks apparent, such as the immense gay male hegemony over that space. Nesma mentioned she did not like being active on the group when I interviewed her. In fact, she further isolated herself after the incident:

Maybe if the incident hadn't happened, I would have been more encouraged to post and ask about things that concern me, or answer people back on matters that I am invested in [...] Before [the incident], I honestly didn't care if anyone knew anything about me offline. Also, the focus was on gay men, and there wasn't any problems with girls living together.

This, in Nesma's opinion, changed after the incident of the rainbow flag. It was the first time she witnessed a crackdown of such a magnitude, as had not experienced any of the previous crackdowns, most notably the queen boat incident. Referring to the rainbow flag profile photo frames that circulated after the attack, she said:

Now, I am avoiding even bringing up the topic [in offline conversations], and I don't share anything on my timeline so people don't make assumptions or categorize me. People were arrested and were severely attacked only for changing their profile photo.

Such backlashes can take many forms online and offline, from shaming, to exclusion from conversations, to extreme cases of reporting the person. Some social media platforms, such as Facebook, provide their users with the option controlling the visibility of their posts by creating different friends lists. I asked Nesma why she does not make use of this privacy feature to continue posting about what she advocates for with trusted circles of friends. She sighed: 
I don't want to be labelled, even if by those who accept who I am. We are a lot more than our sexual orientation; we don't need to have our life gravitating around that sole aspect. I would prefer to go for the style of life I want in total silence and unnoticeability.

\section{The "Leila" Concert as an Event}

In the context of "being and inclusion" and their relation to "presentation and representation," I treat the Rainbow Flag incident as an "event" with an evental site that informs the situation's singularity. In Being and Event, Alain Badiou (2005) provides clear definitions of an event, the evental site, and their relation to each other:

The event is a one multiple made up of, on the one hand, all the multiples which belong to its site, and on the other hand, the event itself... [it] is thus clearly the multiple which both presents its entire site, and, by means of the pure signifier of itself immanent to its own multiple, manages to present the presentation itself, that is, the one of the infinite multiple that it is (p. 179).

The Rainbow Flag incident as an event places it outside the concept of its absolute singularity; it ties it to a series of happenings before and after, hence Badiou's allusion to the relation of past, present and future as imbued in each other. This also perceives an event as creating the unfathomable, or the impossible to think of; yet, the evental site is complicated by the added layers of the event's singularity. Something that seemed completely benign in appearance (i.e. a concert), even to the people who acted as the elements of the event - the multiplicities, can morph into a moment that shifts the political landscape. The state, for instance, was also an element of composing the scene; no longer the scarecrow, it was thrown off-guard and employed violent means to reestablish its dominance.

The concert was at least Mashrou' Leila's third performance in Egypt. In order for a band to be able to perform, they must obtain the permission of many state officials and bodies, such as the ministry of tourism and the ministry of interior, which makes of Mashrou' Leila's presence, along with that of their lead "openly gay" singer, a familiar act. Additionally, it was not the first time that the flag was raised at a Mashrou' Leila concert, an incident I witnessed myself (Egypt Gay, 2015; Scoop Team, 2016). This demarcates the event of the Rainbow Flag incident as a disruption from what is perceived as "normal" because of its singularity and contextual complexities.

Ever since 2013, the rate of arrests in Egypt has massively increased. More than 600 laws have been ratified in a span of 3 years, placing more restrictions on freedom of assembly, speech, purchase, taxes, and labor conditions among others, furthering the asymmetry of power dynamic in Egypt. The "state of exception's" policies for so called "individual behaviors" have sent more people in prisons than out; suppressing dissent, they also created empirical realities in which countless communities are marginalized across struggles. 
From 2001 until today, the public discourse regarding cases of defamation of LGBTIQA++ members and people with non-normative sexualities has shifted greatly, as Dalia Abdel-Hamid remarks, from past witch hunts calling for their deaths, incarcerations, confinement to asylums, or forced service to the army (Mada Masr, 2017b). She says: "more and more people in our [human rights and activism] spheres" are becoming more accepting of the matter being, and more tolerant (2017b). However, she acknowledges that this also changed the discourse and entrapment strategies of the police, as they reduced their monitoring of websites, moving instead to using dating applications like Grindr, Hornet, and Whatsapp (Abdel-Hamid, 2017), and to following online pages. In order to practice mass surveillance, they act like bots, creating fake accounts to trap people then publicly shame them (Fouda, 2014). Not only do these measures infringe the laws of privacy and communication, but they are not in line with Facebook policies either. However, their campaigns of defamation are picked up on by mainstream yellow press that share the discourse of "scandal," with "catchy" headlines such as "arrest of the biggest network of gays" (Al 'Alam al aswad lel 'Askar, 2017; Al Jazeera, 2017; EIFagr, 2017).

Broadening the relations of individuality/solidarity and individuality/nation-state as being and inclusion, Badiou (2005) mathematically illustrated, based on set theory, that the relations between "whole" and "parts" on the one hand, and "one" and "multiple" on the other, are treated as fixed and unidirectional; in fact, they disregard the role of the "multiple" as an element in the presentation of another multiple, which he called belonging, as well as the reading of the "multiple" as a sub-multiple of another, bigger multiple, which he called inclusion (pp. 81-83). Belonging, then, would be the interaction of different struggles together, while inclusion would be the recognition of sub-cultures and sub-communities in broader umbrellas, such as LGBTIQA++. Hence, if we say that the LGBTIQA++ community are "parts" of this society, which they are, that does not mean that they should necessarily have the same demands, since they are treated as subgroups, as my conversation with Ghaly shows. Secondly, neither does it mean that they are associated to the bigger group called the nation, despite the nation-state's desire for being the "whole" that encompasses all of its geography. However, for the nation-state to establish its sense of oneness - that Badiou calls "[the neccesity] of the structure to be structured" (p. 93), it needs to be doubled. In other words, the nation-state creates a meta-structure that secures its presentation against that which it cannot fathom and requires either its elimination or its assimilation.

This "anxiety of the void" (p. 94) means that the nation-state would do all that it can to make sure that the missed gap between the "being" and the inclusion of opinions and identities is covered by the power that reinforces its structure. In that light, social media is the bulling: part of a bigger entity, the Internet, it is a void that needs to be represented, but that also echoes the multitudes of voices that are a "part" in their own representation. In other words, it represents the uniqueness of the multiple that is part of another multiple. In that case, how to make space for the voices within that marginalized multiple, especially in relation to discourses of solidarity? 


\section{Conclusion}

This paper assembled the multiplicities and singularities of an event. The Mashrou' Leila concert in Cairo is an example of an event in the Badiouian sense, inviting us to view present events as singular, as well as a part of a multiple. It also reflects the perceptions of the individuals' voices on social media. Social media played a huge role in contesting identities, as a void for one part - the nation-state, and a terrain for another - the LGBTIQA++ community. It acted as a platform where many dilemmas played out, notably that of the nation/individual (i.e. the one and the multiple) relation; treating the personal as political, the paper also looked at different people's responses to the politicization of their personal. Most importantly, it furthered the understanding of the imagery of the bullring as having more than two contestants, as treating it as a binary would be an over-simplification, and an obliteration of the individuality of the parties discussed. Therefore, it allows us to perceive the LGBTIQA++ community as individuals, as well as a collective contestant, in the same way that feminisms are plural.

To view the nation-state as a non-multiple, yet "one" in the one/multiple equation, would gloss over the fact that the nation-state cannot contain its alleged "parts" (i.e. social media platforms). The nation-state, then, when presented with multiples outside its control, responds with anxiety towards multiplicity, presentations, and representations; totally oblivious to the different individualities within what it purportedly contains, it labels multiplicity as "deviancy." Finally, this paper's aim is to acknowledge and honor the complexities and individualities within, to address the people who find themselves as subjects of research, such as the LGBTIQA++ community, a part of the other multiple that is the MENA region, as individuals, and not solely as representatives of a group, and to distance itself from politics of tokenization. It also hopes to engage further studies on the analysis of discourses, as they are presented and represented. 
Kohl 4.1

\section{Works Cited}

Abdel-Hamid, D. (2017). "The Trap: Punishing Sexual Difference in Egypt (Human Rights)." Egyptian Initiative for Personal Rights. Retrieved from: https://eipr.org/en/publications/trap-punishing-sexualdifference-egypt

Al 'Alam al aswad lel 'Askar. (2017). "من وراء حفل الثواذ بالقاهرة الجديدة أو فرقة مشروع ليلى." YouTube. Retrieved from: https://www.youtube.com/watch?v=j6f7XXBX3go

Al Jazeera, N. (2017, September 25). "احتفال راقص للمنليين في القاهرة تقرير الجزيرة:" Retrieved from: https://www.youtube.com/watch?v=twJ1frBQ1nY

Andrews, L. B. (2012). I Know Who You Are and I Saw What You Did: Social Networks and the Death of Privacy. New York: Free Press.

Badiou, A. (2005). Being and Event. London and New York: Continuum.

Bell, D. (2001). An Introduction to Cybercultures. London: Routledge

Deleuze, G., Guattari, F., Tomlinson, J., \& Burchell III, G. (2014). What Is Philosophy? New York: Columbia University Press.

Egypt Gay, E. (2015, April 7). 'The rainbow flag in Mashrou' Leila concert in Cairo last Friday @hamedleila @mashrou3leila \#Egypt \#arablgbt \#lgbtpic.twitter.com/S0eLovcyb8." [Tweet]. Retrieved from https://twitter.com/egy_gay/status/584111824477511680?lang=en

ElFagr, N. P. (2017, September 23). "بو ابة الفجر: المتليون يحتفلون برفع علمهم في حفل "مشروع لبلي" (صور)" Retrieved from: http://www.elfagr.com/2762347

Fouda, R. (2014, December 30). "Governments and their LGBT / NGOs Fetish." [Blog]. Retrieved from: https://radwafouda.blogspot.com.eg/2014/12/lgbt-fetishism-in-political-systems.html

Fouda, R. (2016). Virtual Bodies: Representations of Gender \& Sexuality in the Virtual Space. Working Paper, AUC.

Gehl, R.W. (2016). "Power/freedom on the dark web: A digital ethnography of the Dark Web Social Network." New Media \& Society, vol. 18, no. 7, pp. 1219-1235.

Green, E. (2013, September 9). "Mapping the 'Geography' of the Internet." The Atlantic. Retrieved from: https://www.theatlantic.com/technology/archive/2013/09/mapping-the-geography-of-theinternet/279434/

Hamama, M. (2017, January 17). "Infinite eyes in the network: Government escalates attack on secure communication." Mada Masr. Retrieved from: https://www.madamasr.com/en/2017/02/10/feature/politics/infinite-eyes-in-the-networkgovernment-escalates-attack-on-secure-communication/

Hine, C. (2015). Ethnography for the Internet: Embedded, Embodied and Everyday. Huntingdon: Bloomsbury International Telecommunication Union (ITU). (2017). "ICT Facts and Figures 2017." Retrieved from: http://mcit.gov.eg/Upcont/Documents/Reports\%20and\%20Documents_692017000_ICT_Facts_Fig ures_2017.pdf

Mada Masr. (2017a). "1/6 - قضية "كوين بوت" Queen Boat (Vol. 1)." YouTube. Retrieved from: https://www.youtube.com/watch?v=i81kMCyVcPI\&list=PL2b4XFUJwARERwAkn3pdAm49bOZrShv $\mathrm{BC}$ 
Mada Masr. (2017b). "5/6 - r حملة ما بعد r - C Crackdown post-2013 (Vol. 1)." YouTube. Retrieved from: https://www.youtube.com/watch?v=yo4W-KsDCCg

Ministry of Communication and Information Technology. (n.d.). "MCIT | Telecommunications - National Broadband Plan." Retrieved from: http://mcit.gov.eg/TeleCommunications/National_Broadband_Plan_eMisr

Norris, C. (2009). Badiou's Being and Event: a reader's guide. London and New York: Continuum.

Patton, P. (1991). "The World Seen From Within: Deleuze and the Philosophy of Events." Theory \& Event, vol. 1, no. 1. https://doi.org/10.1353/tae.1991.0006

Scoop Team. (2016, March 19). "Hamed Sinno Applauds Rainbow Flag At Cairo Concert." Scoop Empire. Retrieved from: http://scoopempire.com/hamed-sinno-applauds-rainbow-flag-cairo-concert/

Simpson, A. (2014). Mohawk interruptus: political life across the borders of settler states. Durham: Duke University Press. 